\title{
Thyroid Uptake and Effective Half-Life of Radioiodine in Thyroid Cancer Patients at Radioiodine Therapy and Follow- Up Whole-Body Scintigraphy Either in Hypothyroidism or Under rhTSH
}

\author{
Robin Bacher, Melanie Hohberg, Markus Dietlein, Markus Wild, Carsten Kobe, Alexander Drzezga, and Matthias Schmidt
}

Department of Nuclear Medicine, University Hospital of Cologne, Cologne, Germany

Adjuvant radioiodine therapy (RITh) for differentiated thyroid carcinoma is performed either with thyroid hormone withdrawal or with administration of recombinant human thyroid-stimulating hormone (rhTSH). Heterogeneous results have been obtained on the impact of the method of patient preparation on thyroid uptake and wholebody effective half-life. A higher radiation exposure using thyroid hormone withdrawal for several weeks compared with rhTSH was reported in prior studies. It was the aim to examine whether these findings are reproducible in a modern protocol with a short interval between surgery and RITh. Methods: A retrospective study was performed on patients admitted for adjuvant RITh for differentiated thyroid carcinoma at the University Hospital of Cologne over a 5-y period from 2010. Dose rate measurements were analyzed for 366 patients, and subgroup analyses were performed for papillary thyroid cancer $(n=341)$ and follicular thyroid cancer $(n=25)$ patients, sex, length of hypothyroidism, and normal versus decreased glomerular filtration rate (GFR). Results: The median interval between surgery and RITh was $18 \mathrm{~d}$ for thyroid hormone withdrawal and $25 \mathrm{~d}$ for rhTSH $(P<0.01)$. The mean thyroid uptake was $4.2 \% \pm 1.8 \%$ for the 300 hypothyroid patients versus $3.8 \% \pm 1.6 \%(P=0.12)$ for the $66 \mathrm{rhTSH}$ patients. Whole-body half-life in the hypothyroid group was significantly longer at $19.3 \pm 7.7 \mathrm{~h}$ versus $16.4 \pm 4.6 \mathrm{~h}$ in the rhTSH group $(P<0.01)$. Results were predominantly influenced by data from the largest subgroup, that is, female papillary thyroid cancer patients. Within this group, whole-body half-life was significantly shorter in the rhTSH treatment arm. Duration of hypothyroidism and a decrease in GFR less than $60 \mathrm{~mL} / \mathrm{min} / 1.73 \mathrm{~m}^{2}$ significantly influenced results, with an increased whole-body halflife occurring in the hypothyroid group. When patients returned for whole-body scintigraphy, thyroid, half-life, and whole-body half-life were significantly shorter in the rhTSH groups, resulting in a low thyroid and remaining-body dose. Conclusion: With a shortening of the time between surgery and adjuvant RITh, thyroid uptake is not significantly changed but whole-body half-life becomes longer in the hypothyroid group. Radiation exposure for most patients is not significantly different. However, patients with a hypothyroid phase of more than $4 \mathrm{wk}$, and in particular those with a decreased GFR, experience higher radiation exposure.

Received Jul. 16, 2018; revision accepted Sep. 25, 2018.

For correspondence or reprints contact: Matthias Schmidt, Oberarzt, Arzt für Nuklearmedizin, FEBNM, Klinik und Poliklinik für Nuklearmedizin, Universitätsklinikum Köln, Department of Nuclear Medicine, University Hospital of Cologne, Kerpener Strasse 62, 50937 Köln/Cologne, Germany.

E-mail: matthias.schmidt@uk-koeln.de

Published online Oct. 12, 2018.

COPYRIGHT (c) 2019 by the Society of Nuclear Medicine and Molecular Imaging.
Key Words: differentiated thyroid carcinoma; radioiodine therapy; dosimetry; thyroid uptake; effective half-life; recombinant human thyroid-stimulating hormone

J Nucl Med 2019; 60:631-637

DOI: $10.2967 /$ jnumed.118.217638

$\mathbf{I}$ Germany, adjuvant radioiodine therapy (RITh) is given after thyroidectomy for differentiated thyroid cancer, except for papillary microcarcinomas, with the aim of improving disease-specific survival (1). International guidelines vary in their recommendations with regard to RITh. The British (2) and American Thyroid Association (3) guidelines are more restrictive, whereas Italian (4) and French (5) guidelines are generally in favor of RITh. Over the years, the time interval set between thyroidectomy and RITh has become shorter. Currently, RITh is often given $2-3$ wk after surgery (1). Previous studies found differences in radiation exposure between patients treated in hypothyroidism versus rhTSH (6-15). The aim was to retrospectively examine thyroid uptake and effective half-life in patients with a shorter time interval between surgery and RITh, thus reflecting current therapeutic standards. A further aim was to characterize thyroid uptake and effective half-life during whole-body scintigraphy performed 6-9 mo after RITh for response assessment.

\section{MATERIALS AND METHODS}

\section{Patients}

From January 1, 2010, to December 31, 2014, 424 patients with a histopathologically confirmed diagnosis of differentiated thyroid cancer after total thyroidectomy underwent RITh at the University Hospital of Cologne. Patients with known metastases or with an initial activity of more than $4,000 \mathrm{MBq}$ of radioiodine $(n=23)$, patients with a latency period between surgery and RITh of more than 4 mo $(n=2)$, and patients with an uptake in the thyroid bed of more than $10 \%$ (rated as incomplete surgery, $n=33$ ) were excluded. Finally, 366 patients were analyzed (341 papillary thyroid carcinoma [PTC] and 25 angioinvasive follicular thyroid carcinoma [FTC] patients) from which 339 patients returned for whole-body scintigraphy 6-9 mo after initial treatment. Patients were prepared with a low-iodine diet.

\section{Laboratory Values: Hypothyroidism Versus rhTSH}

Thyroid-stimulating hormone (TSH), free T4, free T3, thyroglobulin, and thyroglobulin antibodies were measured in hypothyroid patients before administration of radioiodine (Immulite 2000; Diagnostic Products). In the hypothyroid group, no levothyroxine was given after 
histopathologic diagnosis of differentiated thyroid carcinoma whereas in the rhTSH group levothyroxine was initially administered and only withheld for a short time of usually $8 \mathrm{~d}$ (3 d before rhTSH injection until day 2 after radioiodine application). When returning for whole-body scintigraphy after 6-9 mo, most patients received rhTSH with an interruption of levothyroxine for $8 \mathrm{~d}$. To achieve hypothyroidism patients stopped levothyroxine $5 \mathrm{wk}$ before radioiodine application and had intermittent liothyronine in weeks 2 and 3.

At initial adjuvant RITh, 300 patients were treated in hypothyroidism and 66 patients under rhTSH. The decision for hypothyroidism or rhTSH was based on physician counseling and patient preferences. Elder patients and especially those with comorbidities were preferentially prepared with rhTSH. For response assessment, whole-body scintigraphy was almost exclusively done under $\operatorname{rhTSH}(n=312)$, whereas only 27 patients were admitted in hypothyroidism.

\section{Dosimetry and Calculations}

Postradioiodine whole-body uptake was measured immediately after radioiodine application and then twice daily every $12 \mathrm{~h}$ using a calibrated scintillation counter (ISOMED 2101; MED NuklearMedizintechnik Dresden $\mathrm{GmbH}$ ) with a distance of $4.5 \mathrm{~m}$ between the patient and the instrument, ensuring that count rate losses due to dead-time effects of the scintillation counter were negligible. For thyroid measurements, the patient was positioned behind a whole-body lead plate with a hole for neck exposure only while the remaining body was shielded behind the lead plate. Calculations of the cumulated activity and effective half-life for the thyroid and whole body were based on these measurements. For this purpose, a numeric integration was performed for the period of the inpatient stay and a calculated extrapolation for the period thereafter.

The thyroid dose was calculated using the following formula (16):

$$
\mathrm{D}[\mathrm{Gy}]=\tilde{\mathrm{A}}[\mathrm{MBq} * \mathrm{~d}] * \mathrm{E} / \mathrm{M}[\mathrm{g}]
$$

where $\mathrm{E}=2.808 \mathrm{~Gy} * \mathrm{~g} /(\mathrm{MBq} * \mathrm{~d})$. A mass of $1 \mathrm{~g}$ was assumed for the remnant thyroid $\mathrm{M}[\mathrm{g}]$. The average absorbed energy per unit of mass deposited in the target organ (index $\mathrm{k}$ ) was then calculated as a product of the cumulated activity $\left(\tilde{\mathrm{A}}_{h}\right)$ and the corresponding $S$ value $\left(\mathrm{S}_{(\mathrm{h} \leftarrow \mathrm{k})}\right)$ :

$$
\mathrm{D}_{(\mathrm{k} \leftarrow \mathrm{h})}=\tilde{\mathrm{A}}_{\mathrm{h}} * \mathrm{~S}_{(\mathrm{k} \leftarrow \mathrm{h})} .
$$

This equation was used for calculating the absorbed dose in the whole body and remaining body:

$$
\mathrm{D}_{(\mathrm{WB})}=\tilde{\mathrm{A}}_{\mathrm{WB}} * \mathrm{~S}_{(\mathrm{WB} \leftarrow \mathrm{WB})},
$$

where WB is whole-body, $\mathrm{RB}$ is remaining body, and $\mathrm{T}$ is thyroid:

$$
\mathrm{D}_{(\mathrm{RB})}=\tilde{\mathrm{A}}_{\mathrm{RB}} * \mathrm{~S}_{(\mathrm{WB} \leftarrow \mathrm{WB})}+\tilde{\mathrm{A}}_{\mathrm{T}} * \mathrm{~S}_{(\mathrm{WB} \leftarrow \mathrm{T})},
$$

where the cumulated activity of the remaining body is defined as $\tilde{\mathrm{A}}_{\mathrm{RB}}=$ $\tilde{\mathrm{A}}_{\mathrm{WB}}-\tilde{\mathrm{A}}_{\mathrm{T}}$. The therapeutically achieved half-life was estimated from measurements of thyroid and whole-body uptake estimated from readings taken from at least 5 points of uptake. Time-activity curves were generated for calculation of thyroid and whole-body half-life and cumulated activity.

Parameters analyzed were radioiodine activity (MBq) given to the patients, thyroid uptake (\%), thyroid half-life (h), thyroid cumulated activity $\left(\mathrm{MBq}^{*} \mathrm{~d}\right)$, and thyroid residence time (h) as well as whole-body half-life (h), whole-body cumulated activity $\left(\mathrm{MBq}^{*} \mathrm{~d}\right)$ and whole-body residence time (h), and remaining-body dose (mGy). Results were calculated for patients in hypothyroidism versus rhTSH application. As we saw only 25 patients with angioinvasive FTC, calculations were focused on the predominant group of PTC patients. Subgroups included patients of younger versus older age, duration of the hypothyroid period ( $\leq 4 \mathrm{vs}$. $>4 \mathrm{wk})$ and glomerular filtration rate (GFR) $(<60 \mathrm{vs}$. $\geq 60 \mathrm{~mL} / \mathrm{min}$ $1.73 \mathrm{~m}^{2}$ ). GFR was calculated using the CKD-EPI (Chronic Kidney Disease Epidemiology Collaboration) formula (17). IBM SPSS Statistics (64-bit) was used for statistical analysis. Data are expressed as mean \pm SD and 25-75 percentiles in brackets. Groups were compared using the Mann-Whitney test, and the level of significance was set at 0.05 . The institutional review board approved this retrospective study, and the requirement to obtain informed consent was waived.

\section{RESULTS}

\section{Adjuvant RITh}

Patient characteristics are given in Table 1, and these parameters did not differ between groups. Patients in hypothyroidism had a mean TSH greater than $30 \mathrm{mU} / \mathrm{L}$ (25 percentile $31.1 \mathrm{mU} / \mathrm{L}-75$ percentile $60.4 \mathrm{mU} / \mathrm{L}$ ). The mean TSH in FTC patients was higher than in PTC patients (63.2 [28.9-87.7] mU/L vs. 51.4 [31.6-60.0] $\mathrm{mU} / \mathrm{L})$. Patients under $60 \mathrm{y}$ of age had a higher TSH than those of $\geq 60$ y (52.8 [32.0-63.2] vs. 45.9 [29.3-48.5] mU/L). TSH increased over time without levothyroxine: TSH was 47.6 (31.054.8) $\mathrm{mU} / \mathrm{L}$ in hypothyroid patients off levothyroxine for $\leq 4 \mathrm{wk}$ whereas TSH was 75.9 (41.6-112.7) $\mathrm{mU} / \mathrm{L}$ in patients who were without levothyroxine for $>4 \mathrm{wk}$. GFR had no influence on TSH increase: TSH was 55.7 (29.9-69.6) $\mathrm{mU} / \mathrm{L}$ in patients with GFR $<$ $60 \mathrm{~mL} / \mathrm{min} / 1.73 \mathrm{~m}^{2}$, and TSH was $52.1(33.0-61.2) \mathrm{mU} / \mathrm{L}$ in patients with GFR $\geq 60 \mathrm{~mL} / \mathrm{min} / 1.73 \mathrm{~m}^{2}$.

Table 2 provides dosimetric results for all patients. The median interval between surgery and adjuvant radioiodine was $18 \mathrm{~d}$ in the hypothyroid and $25 \mathrm{~d}$ in the rhTSH group $(P<0.001)$.

TABLE 1

Patient Characteristics

\begin{tabular}{llll}
\hline \multicolumn{1}{c}{ Characteristic } & Hypothyroid, $n\left(\%^{*}\right)$ & rhTSH, $n\left(\%{ }^{*}\right)$ & $P$ \\
\hline Sex (female/male) & $216(82.4) / 84(80.8)$ & $46(17.6) / 20(19.2)$ & 0.71 \\
\hline Age $(<60 / \geq 60$ y) & $244(83.3) / 56(76.7)$ & $49(16.7) / 17(23.3)$ & 0.19 \\
Histology (PTC/FTC) & $281(82.4) / 19(76.0)$ & $60(17.6) / 6(24.0)$ & 0.42 \\
T (T $\leq$ T2/>T2) & $229(83.3) / 70(78.7)$ & $46(16.7) / 19(21.3)$ & 0.32 \\
N (N0/N1) & $203(79.0) / 81(88.0)$ & $54(21.0) / 11(12.0)$ & 0.06 \\
\hline
\end{tabular}

${ }^{*}$ Row wise. 
TABLE 2

Dosimetric Results for All Patients

\begin{tabular}{|c|c|c|c|}
\hline Parameters of iodine kinetics & Hypothyroid $(n=300)$ & rhTSH $(n=66)$ & $P$ \\
\hline Activity (MBq) & $3,417 \pm 599$ & $3,284 \pm 728$ & 0.34 \\
\hline Thyroid uptake (\%) & $4.2 \pm 1.8$ & $3.8 \pm 1.6$ & 0.12 \\
\hline Thyroid half-life $(\mathrm{h})$ & $30.6 \pm 15.0$ & $30.1 \pm 14.6$ & 0.86 \\
\hline Thyroid cumulated activity $\left(\mathrm{MBq}^{\star} \mathrm{d}\right)$ & $287 \pm 209$ & $250 \pm 192$ & 0.08 \\
\hline Thyroid residence time $(\mathrm{h})$ & $2.1 \pm 1.5$ & $1.9 \pm 1.3$ & 0.26 \\
\hline Thyroid dose (Gy) & $801 \pm 587$ & $702 \pm 540$ & 0.09 \\
\hline Whole-body half-life (h) & $19.3 \pm 7.7$ & $16.4 \pm 4.6$ & $\leq 0.01$ \\
\hline Whole-body cumulated activity $\left(\mathrm{MBq}^{*} \mathrm{~d}\right)$ & $1,695 \pm 547$ & $1599 \pm 498$ & 0.31 \\
\hline Whole-body residence time $(\mathrm{h})$ & $11.9 \pm 3.3$ & $11.8 \pm 3.4$ & 0.64 \\
\hline Remaining-body dose (mGy) & $90 \pm 30$ & $86 \pm 27$ & 0.36 \\
\hline
\end{tabular}

No significant differences in dosimetric results were found except with regard to whole-body half-life. However, the wholebody half-life was less than $1 \mathrm{~d}$ in both groups and therefore resulted in no statistically significant differences in radiation exposure.

The largest subgroup were PTC patients (Table 3). Whole-body half-life was significantly shorter for female rhTSH patients, and less than $1 \mathrm{~d}$ in both male and female PTC patients. This did not result in any significant differences in thyroid or whole-body cumulated activities. The difference was more pronounced in patients younger than $60 \mathrm{y}$ of age and less in patients aged $60 \mathrm{y}$ or older, with a higher thyroid uptake in hypothyroid patients younger than $60(P=0.07)$, probably due to the higher TSH in patients under $60 \mathrm{y}$. Neither thyroid nor remaining-body dose were significantly different. In the male PTC group, the mean remaining-body dose was $92 \mathrm{mGy}$ for hypothyroid and $91 \mathrm{mGy}$ for rhTSH patients whereas in the female PTC group, values were 89 and $85 \mathrm{mGy}$, respectively $(P>0.05)$.

When analyzing duration of hypothyroidism, a long period of at least 4 wk between surgery and adjuvant RITh was associated with a significantly longer whole-body half-life in the hypothyroid in comparison to the rhTSH group (Table 4).
A reduced GFR had pronounced effects on the results. In hypothyroid patients with a GFR $<60 \mathrm{~mL} / \mathrm{min} / 1.73 \mathrm{~m}^{2}$, wholebody half-life was significantly different between groups and whole-body cumulated activity was significantly higher in the hypothyroid group, resulting in a higher remaining-body dose with a mean value of $127 \mathrm{mGy}$ in the hypothyroid versus $87 \mathrm{mGy}$ in the rhTSH group. Thus, renal function significantly influenced thyroid uptake and remaining-body dose (Table 5).

\section{Response Evaluation with Whole-Body Scintigraphy}

Patients treated under hypothyroidism had a mean TSH $>30$ mU/L: PTC patients had a TSH of 79.3 (47.4-110.9) $\mathrm{mU} / \mathrm{L}$ and 1 FTC patient had a TSH of $83.9 \mathrm{mU} / \mathrm{L}$. Patients younger than $60 \mathrm{y}$ had a higher TSH than those who were older (83.2 [49.2-111.8] vs. 49.2 [27.4-60.0] $\mathrm{mU} / \mathrm{L})$.

Almost all patients had their examination for response evaluation under rhTSH, and only 27 patients (26 PTC and 1 FTC) were admitted in hypothyroidism. For the whole group and for PTC patients, values differed significantly between hypothyroidism and rhTSH with significantly lower values in the rhTSH group despite a slight, nonsignificant elevation of applied activity (Table 6). This was seen in both male and female PTC patients.

TABLE 3

Dosimetric Results for Male and Female PTC Patients

\begin{tabular}{|c|c|c|c|c|c|c|}
\hline \multirow[b]{2}{*}{ Parameters of iodine kinetics } & \multicolumn{3}{|c|}{ Male PTC patients } & \multicolumn{3}{|c|}{ Female PTC patients } \\
\hline & $\begin{array}{l}\text { Hypothyroid } \\
(n=79)\end{array}$ & $\begin{array}{c}\text { rhTSH } \\
(n=16)\end{array}$ & $P$ & $\begin{array}{l}\text { Hypothyroid } \\
(n=202)\end{array}$ & $\begin{array}{l}\text { rhTSH } \\
(n=44)\end{array}$ & $P$ \\
\hline Activity (MBq) & $3,480 \pm 515$ & $3,586 \pm 441$ & 0.19 & $3,382 \pm 644$ & $3,161 \pm 791$ & 0.04 \\
\hline Thyroid uptake (\%) & $4.9 \pm 2.0$ & $4.1 \pm 1.3$ & 0.14 & $3.9 \pm 1.7$ & $3.6 \pm 1.7$ & 0.32 \\
\hline Thyroid half-life $(h)$ & $38.1 \pm 19.9$ & $32.3 \pm 15.5$ & 0.22 & $28.0 \pm 12.0$ & $29.6 \pm 14.7$ & 0.57 \\
\hline Thyroid cumulated activity $\left(\mathrm{MBq}^{*} \mathrm{~d}\right)$ & $406 \pm 284$ & $298 \pm 180$ & 0.21 & $242 \pm 152$ & $225 \pm 169$ & 0.19 \\
\hline Thyroid residence time $(\mathrm{h})$ & $2.9 \pm 2.1$ & $2.0 \pm 1.1$ & 0.16 & $1.8 \pm 1.1$ & $1.8 \pm 1.3$ & 0.68 \\
\hline Thyroid dose (Gy) & $1,139 \pm 797$ & $836 \pm 505$ & 0.21 & $674 \pm 427$ & $630 \pm 475$ & 0.22 \\
\hline Whole-body half-life $(h)$ & $22.7 \pm 11.6$ & $18.0 \pm 6.6$ & 0.06 & $18.1 \pm 5.1$ & $15.9 \pm 3.7$ & 0.01 \\
\hline Whole-body cumulated activity $\left(\mathrm{MBq}^{*} \mathrm{~d}\right)$ & $1,859 \pm 557$ & $1,754 \pm 350$ & 0.53 & $1,622 \pm 527$ & $1,547 \pm 548$ & 0.46 \\
\hline Whole-body residence time $(h)$ & $12.9 \pm 3.4$ & $11.8 \pm 2.0$ & 0.23 & $11.6 \pm 3.1$ & $11.9 \pm 3.9$ & 0.86 \\
\hline Remaining-body dose (mGy) & $92 \pm 28$ & $91 \pm 20$ & 0.95 & $89 \pm 30$ & $85 \pm 30$ & 0.45 \\
\hline
\end{tabular}


TABLE 4

Dosimetric Results for PTC Patients with More Than 4-Week Hypothyroidism in Comparison to rhTSH PTC Patients

\begin{tabular}{|c|c|c|c|}
\hline Parameters of iodine kinetics & Hypothyroid $(n=31)$ & $\operatorname{rhTSH}(n=60)$ & $P$ \\
\hline Activity (MBq) & $3,298 \pm 714$ & $3,274 \pm 736$ & 0.79 \\
\hline Thyroid uptake (\%) & $4.5 \pm 1.8$ & $3.7 \pm 1.6$ & 0.07 \\
\hline Thyroid half-life $(\mathrm{h})$ & $38.0 \pm 19.9$ & $30.3 \pm 14.8$ & 0.05 \\
\hline Thyroid cumulated activity $\left(\mathrm{MBq}^{\star} \mathrm{d}\right)$ & $351 \pm 272$ & $244 \pm 174$ & 0.07 \\
\hline Thyroid residence time $(\mathrm{h})$ & $2.6 \pm 2.0$ & $1.8 \pm 1.2$ & 0.09 \\
\hline Thyroid dose (Gy) & $985 \pm 763$ & $685 \pm 488$ & 0.07 \\
\hline Whole-body half-life (h) & $21.6 \pm 12.8$ & $16.5 \pm 4.7$ & 0.02 \\
\hline Whole-body cumulated activity $\left(\mathrm{MBq}^{\star} \mathrm{d}\right)$ & $1,682 \pm 530$ & $1,602 \pm 508$ & 0.54 \\
\hline Whole-body residence time $(\mathrm{h})$ & $12.3 \pm 2.7$ & $11.9 \pm 3.5$ & 0.34 \\
\hline Remaining-body dose (mGy) & $85 \pm 28$ & $87 \pm 28$ & 0.88 \\
\hline
\end{tabular}

\section{DISCUSSION}

This retrospective analysis produced 2 main results. First, with shortening of the time between thyroidectomy and adjuvant RITh, the use of rhTSH resulted in a significantly shorter whole-body half-life. However, the mean absolute difference was only $2.9 \mathrm{~h}$, and this did not translate into significant differences in the remaining-body dose. Nevertheless, in patients with more than 4 wk between surgery and RITh and particularly in those with a low GFR, remaining-body dose was significantly lower in the rhTSH group. Diminished GFR is a key factor, with significant influence on radiation exposure, and accordingly, patients with a GFR $<60$ $\mathrm{mL} / \mathrm{min} / 1.73 \mathrm{~m}^{2}$ in hypothyroidism had a significantly higher radiation exposure than did the group treated under rhTSH. Second, whole-body scintigraphy for response assessment is associated with low radiation exposure and currently in our clinic done almost exclusively with rhTSH.

Table 7 compiles publications comparing the effect of hypothyroidism and rhTSH on whole-body dose, half-life, or residence time (6-15). Most publications are based on studies with a limited number of patients. Our retrospective analysis comprises the largest number of patients analyzed so far and only the studies of Menzel et al. (6) and Remy et al. (10) analyzed more than 200 patients. The age group is comparable in all studies analyzing patients with a mean age in the late 40 s or 50 s.

In comparison to previously published studies, our patients had a rather short time interval between surgery and adjuvant RITh of $18 \mathrm{~d}$. Only in the study of Grenfell et al. (15) was this interval within the same range, and they found no differences in wholebody half-life between the rhTSH and hypothyroidism groups. TSH values in the literature show that these are usually much higher than the commonly accepted threshold of $30 \mathrm{mU} / \mathrm{L}$. Former prospective randomized controlled trials had longer hypothyroid intervals of several weeks $(18,19)$.

Most studies report lower whole-body radiation exposure in the rhTSH versus hypothyroid group (6-14). Comparison of these publications reveals considerable differences in methodology, especially in the methods for measuring thyroid uptake and effective half-life. Both parameters, thyroid uptake and effective half-life, are key determinants of radiation exposure. Carvalho et al. (Portuguese Oncology Institute, Lisbon, Portugal) used a radiation detector to measure whole-body retention at a distance of $1 \mathrm{~m}$ $48 \mathrm{~h}$ after radioiodine application (12). No serial measurements were performed (12). Ravichandran et al. used sequential measurements with a digital autoranging $\beta-\gamma$ survey instrument at

TABLE 5

Dosimetric Results for Hypothyroid PTC Patients with GFR $\geq$ Versus $<60 \mathrm{~mL} / \mathrm{min} / 1.73 \mathrm{~m}^{2}$ in Comparison to rhTSH PTC Patients

\begin{tabular}{|c|c|c|c|c|c|c|}
\hline Parameters of iodine kinetics & $\begin{array}{l}\text { Hypothyroid normal } \\
\text { GFR }(n=227)\end{array}$ & $\begin{array}{l}\text { rhTSH } \\
(n=60)\end{array}$ & $P$ & $\begin{array}{l}\text { Hypothyroid low } \\
\text { GFR }(n=20)\end{array}$ & $\begin{array}{l}\text { rhTSH } \\
(n=60)\end{array}$ & $P$ \\
\hline Activity (MBq) & $3,385 \pm 634$ & $3,274 \pm 736$ & 0.36 & $3,508 \pm 512$ & $3,274 \pm 736$ & 0.23 \\
\hline Thyroid uptake (\%) & $4.1 \pm 1.8$ & $3.7 \pm 1.6$ & 0.28 & $4.7 \pm 1.5$ & $3.7 \pm 1.6$ & 0.02 \\
\hline Thyroid half-life $(\mathrm{h})$ & $31.2 \pm 15.5$ & $30.3 \pm 14.8$ & 0.73 & $27.2 \pm 8.3$ & $30.3 \pm 14.8$ & 0.76 \\
\hline Thyroid cumulated activity $\left(\mathrm{MBq}^{*} \mathrm{~d}\right)$ & $277 \pm 195$ & $244 \pm 174$ & 0.14 & $311 \pm 171$ & $244 \pm 174$ & 0.06 \\
\hline Thyroid residence time $(\mathrm{h})$ & $2.0 \pm 1.5$ & $1.8 \pm 1.2$ & 0.37 & $2.1 \pm 1.1$ & $1.8 \pm 1.2$ & 0.16 \\
\hline Thyroid dose (Gy) & $774 \pm 548$ & $685 \pm 488$ & 0.17 & $873 \pm 481$ & $685 \pm 488$ & 0.06 \\
\hline Whole-body half-life (h) & $19.4 \pm 8.0$ & $16.5 \pm 4.7$ & $\leq 0.01$ & $19.0 \pm 4.5$ & $16.5 \pm 4.7$ & 0.02 \\
\hline Whole-body cumulated activity $\left(\mathrm{MBq}^{*} \mathrm{~d}\right)$ & $1,619 \pm 473$ & $1,602 \pm 508$ & 0.89 & $2,325 \pm 807$ & $1,602 \pm 508$ & $\leq 0.01$ \\
\hline Whole-body residence time $(\mathrm{h})$ & $11.6 \pm 2.8$ & $11.9 \pm 3.5$ & 0.88 & $15.7 \pm 4.7$ & $11.9 \pm 3.5$ & $\leq 0.01$ \\
\hline Remaining-body dose (mGy) & $86 \pm 25$ & $87 \pm 28$ & 0.94 & $127 \pm 45$ & $87 \pm 28$ & $\leq 0.01$ \\
\hline
\end{tabular}


TABLE 6

Dosimetric Results for Whole-Body Scintigraphy

\begin{tabular}{|c|c|c|c|}
\hline Parameters of iodine kinetics & Hypothyroid $(n=27)$ & rhTSH $(n=312)$ & $P$ \\
\hline Activity (MBq) & $403 \pm 88$ & $412 \pm 83$ & 0.11 \\
\hline Thyroid uptake (\%) & $4.8 \pm 3.5$ & $3.6 \pm 5.2$ & $\leq 0.01$ \\
\hline Thyroid half-life $(h)$ & $15.0 \pm 2.6$ & $12.5 \pm 3.1$ & $\leq 0.01$ \\
\hline Thyroid cumulated activity $\left(\mathrm{MBq}^{\star} \mathrm{d}\right)$ & $18 \pm 9$ & $14 \pm 12$ & $\leq 0.01$ \\
\hline Thyroid residence time $(\mathrm{h})$ & $1.1 \pm 0.5$ & $0.8 \pm 0.7$ & $\leq 0.01$ \\
\hline Thyroid dose (Gy) & $51 \pm 27$ & $39 \pm 23$ & $\leq 0.01$ \\
\hline Whole-body half-life $(h)$ & $13.6 \pm 3.7$ & $11.5 \pm 4.0$ & $\leq 0.01$ \\
\hline Whole-body cumulated activity $\left(\mathrm{MBq}^{*} \mathrm{~d}\right)$ & $197 \pm 69$ & $169 \pm 74$ & 0.01 \\
\hline Whole-body residence time $(\mathrm{h})$ & $11.6 \pm 3.1$ & $9.9 \pm 4.2$ & $\leq 0.01$ \\
\hline Remaining-body dose (mGy) & $11 \pm 4$ & $10 \pm 3$ & 0.01 \\
\hline
\end{tabular}

$1 \mathrm{~m}$ in the air providing $\mu \mathrm{Sv} / \mathrm{h}(11,13)$. Grenfell et al. (Royal Adelaide Hospital, Australia) took serial measurements in $\mu \mathrm{Sv} / \mathrm{h}$ at a distance of $1 \mathrm{~m}$ (15). Hänscheid et al. (Würzburg, Germany) combined whole-body probe measurements, scintigraphic wholebody imaging, and blood sampling (8). One important aspect of the study of Hänscheid et al. was that the variability of the results increased with a lowering of the distance between patient and measurement device. The advantage of our methodology is that the selected distance of $4.5 \mathrm{~m}$ between patient and detector minimizes count rate losses due to dead-time effects of the scintillation counter. In addition, our results are fairly robust with regard to minimal differences in patient positioning, which may occur in the course of serial measurements. Other authors used blood samples or calculated a red-marrow absorbed dose, which we did not do in our retrospective analysis $(8,9,14)$.

Absolute values for whole-body half-life differ in the literature. Ravichandran et al. reported about $16.45 \mathrm{~h}$ in the hypothyroidism group versus $12.35 \mathrm{~h}$ in the rhTSH group $(11,13)$. Our values for whole-body half-life were longer with $22.7 \pm 11.6 \mathrm{~h}$ for hypothyroid male and $18.1 \pm 5.1 \mathrm{~h}$ for hypothyroid female patients whereas in the rhTSH group values were $18.0 \pm 6.6 \mathrm{~h}$ for male and $15.9 \pm$ $3.7 \mathrm{~h}$ for female patients. However, Ravichandran et al. also reported a whole-body half-life of $22 \mathrm{~h}$ in a previous cohort of patients, which compares well with our data (11).

It is well established that thyroid half-life is longer than wholebody half-life, as the thyroid stores thyroid hormones. In male hypothyroid patients, thyroid half-life was $38.1 \pm 19.9 \mathrm{~h}$ whereas in the rhTSH group it was $32.3 \pm 15.5 \mathrm{~h}$. Ravichandran et al. measured $48.2 \mathrm{~h}$ in $8 \mathrm{rhTSH}$ patients $(11,13)$. Current developments in radioiodine therapy for differentiated thyroid cancer decrease the administered activity. Lower ${ }^{131}$ I activity could potentially be used especially in hypothyroid patients aiming to achieve comparable thyroid doses as in the rhTSH group and resulting in a more balanced residual body dose.

Iodine kinetics are influenced by the method of patient preparation: a higher renal clearance of radioiodine under rhTSH reduces the mass of radioiodine available for transport into thyroid tissue. This may explain why thyroid uptake was lower in the

TABLE 7

Literature Compilation of Dosimetric Studies Examining lodine Kinetics in Hypothyroid and rhTSH Patients

\begin{tabular}{|c|c|c|c|c|c|c|}
\hline $\begin{array}{c}\text { First author and year } \\
\text { of publication }\end{array}$ & $\begin{array}{c}\mathrm{THW} / \mathrm{rhTSH} \\
(n)\end{array}$ & $\begin{array}{l}\text { Age THW/ } \\
\text { rhTSH (y) }\end{array}$ & $\begin{array}{l}\text { Latency } \\
\text { OP-RIT (d) }\end{array}$ & $\begin{array}{l}\text { THW TSH } \\
(\mathrm{mU} / \mathrm{L})\end{array}$ & $\begin{array}{l}\text { Body dose, half-life } \\
\text { or residence time }\end{array}$ & $\begin{array}{l}\text { Thyroid dose, half-life } \\
\text { or residence time }\end{array}$ \\
\hline Menzel 2003 (6) & $163 / 64$ & $50 / 57$ & $\geq 28$ & $\varnothing \sim 50$ & rhTSH $<$ THW & $?$ \\
\hline Sisson $2003(7)$ & $87 / 10$ & $44 / ?$ & $?$ & $\varnothing 117$ & rhTSH $<$ THW & $?$ \\
\hline Hänscheid 2006 (8) & $33 / 29$ & $? / ?$ & $?$ & $\varnothing 84$ & rhTSH $<$ THW & rhTSH $>$ THW \\
\hline Vaiano 2007 (9) & $29 / 17$ & $46 / 52$ & $\geq 28$ & $?$ & rhTSH $<$ THW & rhTSH $>$ THW \\
\hline Remy 2008 (10) & $218 / 36$ & $48 / 44$ & $\geq 35$ & $\varnothing 69$ & rhTSH $<$ THW & $?$ \\
\hline Carvalho 2012 (12) & $50 / 50$ & $50 / 48$ & $\geq 56$ & $\varnothing 59$ & rhTSH $<$ THW & $?$ \\
\hline Ravichandran 2014 (13) & $81 / 22$ & $? / ?$ & $\geq 35$ & $?$ & rhTSH $<$ THW & rhTSH $<$ THW \\
\hline Grenfell 2015 (15) & $31 / 19$ & $49 / 48$ & 21 (median) & $?$ & $\mathrm{rhTSH}=\mathrm{THW}$ & $?$ \\
\hline Guo 2015 (14) & $9 / 6$ & $41 / 58$ & $\geq 28$ & $?$ & rhTSH $<$ THW & $?$ \\
\hline Ravichandran 2016 (32) & $28 / 14$ & $? / ?$ & $\geq 28$ & $\varnothing 88$ & rhTSH $<$ THW & $?$ \\
\hline Data presented in this publication & $281 / 60$ & $46 / 51$ & 18 (median) & $\varnothing 51$ & $\mathrm{rhTSH}=\mathrm{THW}$ & $\mathrm{rhTSH}=\mathrm{THW}$ \\
\hline
\end{tabular}


rhTSH group. However, the differences we observed, like those of Hänscheid et al. (8), were not statistically significant. Our findings are supported by compartment model calculations. For a given transfer coefficient, the maximal uptake and the residence time in the target tissue depend almost linearly on the blood residence time, which is inversely proportional to the renal clearance (8). Other parameters such as ingestion of stable iodine may also influence uptake. In 1 levothyroxine molecule, the iodine atomic weight accounts for two thirds of the entire levothyroxine molecular weight. Thus, a daily dose of $100-150 \mu \mathrm{g}$ of levothyroxine represents a daily intake of $70-100 \mu \mathrm{g}$ of iodine (14). At least parts of iodine are made biologically available. Löffler et al. showed that urinary iodine excretion was significantly higher in patients under rhTSH and levothyroxine medication in comparison to hypothyroidism (20). The duration of pausing levothyroxine before radioiodine therapy should therefore influence thyroid uptake.

The absorbed dose to the remnant is difficult to calculate and any reported values must be interpreted with caution. The remnant volume cannot usually be measured precisely shortly after operation and calculations may assume volumes as small as $1 \mathrm{~mL}$ (8). Therefore, it was suggested to rather rely on mean residence time instead of remnant absorbed doses. Remnant residence time depends on both uptake and half-time and is proportional to the energy deposited in the remnant volume (8).

Diminished kidney function appears to be a key component for radiation exposure (21-23). Coura-Filho et al. reported on a significant GFR decrease from $94 \pm 19$ to $76 \pm 16 \mathrm{~mL} / \mathrm{min} / 1.73 \mathrm{~m}^{2}$ $(P=0.009)$ in 14 hypothyroid patients $(\mathrm{TSH}>30 \mu \mathrm{IU} / \mathrm{mL})$ while GFR was preserved under rhTSH with $91 \pm 18 \mathrm{~mL} / \mathrm{min} /$ $1.73 \mathrm{~m}^{2}$ at baseline and $93 \pm 15 \mathrm{~mL} / \mathrm{min} / 1.73 \mathrm{~m}^{2}$ after rhTSH (21). Hypothyroidism is known to decrease effective renal plasma flow and GFR (22). As the kidneys express thyroid-related genes, TSH may have a direct effect on kidney function (23).

In our study we used a short-term levothyroxine withdrawal (3 d before rhTSH injection until day 2 after radioiodine application) in the group that received rhTSH. The short-term levothyroxine withdrawal is used to reduce iodine intake (20). In an earlier group of patients, we did not observe the development of hypothyroidism within a few days of levothyroxine withdrawal. However, small influences on kidney function during short-term levothyroxine withdrawal cannot be excluded. Grenfell et al. failed to detect a significant difference in effective half-life between rhTSH and hypothyroidism (15). These authors found an effective half-life of $13.29 \pm 6.29 \mathrm{~h}$ in hypothyroidism versus $11.51 \pm 5.28 \mathrm{~h}$ under $\operatorname{rhTSH}(P=0.761)$. Though effective half-life was longer in the hypothyroidism group, the difference was not statistically significant. This may be explained by the small patient group with 31 hypothyroid patients and 19 patients under rhTSH but it may also reflect the relatively short hypothyroid period. Most patients had a hypothyroid period of less than $3 \mathrm{wk}$. As an explanation for their findings, the authors assume that the decrease in renal clearance was less pronounced than that observed in other studies (15).

There are potential limitations due to our retrospective data analysis. Patients in the rhTSH group were about $9 \mathrm{y}$ older than the patients treated in hypothyroidism. This may reflect the clinical decision to treat patients of increasing age preferentially with rhTSH due to comorbidities. A reduced kidney function was one aspect to use rhTSH. The rate of patients with a GFR $<60 \mathrm{~mL} /$ min was $8.1 \%$ in hypothyroid patients and thus slightly higher than the $5.7 \%$ in rhTSH-stimulated patients $(P=0.545)$. Patients with cardiac dysfunction or some psychiatric conditions are preferentially prepared with rhTSH $(24,25)$.

It is generally agreed that the use of rhTSH provides a better quality of life in comparison to hypothyroidism (26-28). We did not measure quality of life in our patients, but from clinical experience it can be said that the avoidance of hypothyroidism provided a better quality of life. In addition, the injection of rhTSH is very well tolerated in almost all patients, and side effects are either nonexistent or negligible.

The use of rhTSH is associated with drug costs (26) but these are counterbalanced in the German DRG system. The costs of rhTSH may also be counterbalanced by reduced absence from work. rhTSH was associated with a significantly shorter hospital stay in our patients. However, its exact economic impact is difficult to ascertain as there are considerable differences in the healthcare systems between countries.

It is common practice in Germany to perform whole-body scintigraphy in combination with measurements of stimulated thyroglobulin for response assessment 6-9 mo after radioiodine therapy. Results of whole-body scintigraphy and stimulated thyroglobulin level determine response and prognoses, for example, excellent response is usually defined as a TSH-stimulated thyroglobulin of $<1$ $\mathrm{ng} / \mathrm{mL}$ in the absence of structural or functional evidence of disease (and in the absence of antithyroglobulin antibodies) and with no pathologic uptake on whole-body scintigraphy. In our patients, dosimetric results at whole-body scintigraphy were more favorable when using rhTSH, with a remaining-body dose as low as $10 \mathrm{mGy}$.

Worldwide, the use of whole-body scintigraphy is a controversial discussion. In our department, we do not rely on stimulated thyroglobulin measurements only because there are patients with iodine-avid metastases without measurable thyroglobulin. In our understanding, radioiodine therapy is done to eliminate iodineconcentrating thyroid remnants and metastatic tissue and the reason to perform whole-body scintigraphy is to demonstrate the absence of such tissue, especially the absence of iodine-avid metastases. The result is crucial to compare whole-body scintigraphy with subsequent examinations in the case of suspicion of recurrence. A newly iodine-avid lesion in comparison to previously normal findings indicates recurrence. Whole-body scintigraphy can be done with little radiation exposure currently. A low thyroglobulin level does not exclude the presence of iodineavid metastases: in a recent publication Campennì et al. identified 82 of $570(14.4 \%)$ patients with metastases at initial evaluation of whom 73 patients $(90.2 \%)$ had thyroglobulin levels $<1 \mathrm{ng} / \mathrm{mL}$ (29). Nascimento et al. found disease persistence or recurrent disease in 8 of $242(3.3 \%)$ with iodine-avid lesions despite a normal thyroglobulin level (30). Gonzales-Carvalho et al. showed that a complete omission of whole-body scintigraphy in the surveillance of differentiated thyroid carcinoma is justified once whole-body scintigraphy is negative and stimulated thyroglobulin is below the functional sensitivity (with no evidence of thyroglobulin antibodies), as patients showing this combination of test results especially 12 mo after radioiodine therapy show an at worst marginal risk of recurrence (31).

\section{CONCLUSION}

This retrospective analysis of 366 patients, comparing hypothyroidism with rhTSH for adjuvant RITh and whole-body scintigraphy, showed a significantly lower whole-body half-life for the rhTSH groups. The short whole-body half-life of less than $1 \mathrm{~d}$ in both groups 
resulted in roughly equal dosimetric results for the entire patient cohort. However, subgroups could be defined between which more differences emerged. Hypothyroidism of more than $4 \mathrm{wk}$ and especially a decreased GFR resulted in higher radiation exposure in the hypothyroid versus rhTSH group. In our clinic, whole-body scintigraphy is currently almost exclusively done after rhTSH and was associated with a low thyroid- and remaining-body dose.

\section{DISCLOSURE}

This work was financially supported by Sanofi Genzyme. The funders had no role in study design, data collection and analysis, decision to publish, or preparation of the manuscript. No other potential conflict of interest relevant to this article was reported.

\section{REFERENCES}

1. Dietlein M, Eschner W, Grünwald F, et al. Procedure guidelines for radioiodine therapy of differentiated thyroid cancer. Version 4. Nuklearmedizin. 2016;55:77-89.

2. Perros P, Boelaert K, Colley S, et al. British Thyroid Association. Guidelines for the management of thyroid cancer. Clin Endocrinol (Oxf). 2014;81(suppl1):1-122.

3. Haugen BR, Alexander EK, Bible KC, et al. 2015 American Thyroid Association management guidelines for adult patients with thyroid nodules and differentiated thyroid cancer: The American Thyroid Association Guidelines Task Force on Thyroid Nodules and Differentiated Thyroid Cancer. Thyroid. 2016;26:1-133.

4. Pacini F, Brianzoni E, Durante C, et al. Recommendations for post-surgical thyroid ablation in differentiated thyroid cancer: a 2015 position statement of the Italian Society of Endocrinology. J Endocrinol Invest. 2016;39:341-347.

5. Zerdoud S, Giraudet AL, Leboulleux S, et al. Radioactive iodine therapy, molecular imaging and serum biomarkers for differentiated thyroid cancer: 2017 guidelines of the French Societies of Nuclear Medicine, Endocrinology, Pathology, Biology, Endocrine Surgery and Head and Neck Surgery. Ann Endocrinol (Paris). 2017;78:162-175.

6. Menzel C, Kranert WT, Döbert N, et al. rhTSH stimulation before radioiodine therapy in thyroid cancer reduces the effective half-life of ${ }^{131} \mathrm{I}$. J Nucl Med. 2003;44:1065-1068.

7. Sisson JC, Shulkin BL, Lawson S. Increasing efficacy and safety of treatments of patients with well-differentiated thyroid carcinoma by measuring body retentions of ${ }^{131}$ I. J Nucl Med. 2003;44:898-903.

8. Hänscheid H, Lassmann M, Luster M, et al. Iodine biokinetics and dosimetry in radioiodine therapy of thyroid cancer: procedures and results of a prospective international controlled study of ablation after rhTSH or hormone withdrawal. J Nucl Med. 2006;47:648-654.

9. Vaiano A, Claudio Traino A, Boni G, et al. Comparison between remnant and red-marrow absorbed dose in thyroid cancer patients submitted to ${ }^{131} \mathrm{I}$ ablative therapy after rh-TSH stimulation versus hypothyroidism induced by L-thyroxine withdrawal. Nucl Med Commun. 2007;28:215-223.

10. Remy H, Borget I, Leboulleux S, et al. ${ }^{131}$ I effective half-life and dosimetry in thyroid cancer patients. $J$ Nucl Med. 2008;49:1445-1450.

11. Ravichandran R, Binukmumar J, Saadi AA. Estimation of effective half-life of clearance of radioactive iodine $\left({ }^{131} \mathrm{I}\right)$ in patients treated for hyperthyroidism and carcinoma thyroid. Indian J Nucl Med. 2010;25:49-52.

12. Carvalho MR, Ferreira TC, Leite V. Evaluation of whole-body retention of iodine-131 $\left({ }^{131} \mathrm{I}\right)$ after postoperative remnant ablation for differentiated thyroid carcinoma: thyroxine withdrawal versus rhTSH administration-a retrospective comparison. Oncol Lett. 2012;3:617-620.

13. Ravichandran R, Al Saadi A, Al Balushi N. Radioactive body burden measurements in ${ }^{131}$ iodine therapy for differentiated thyroid cancer: effect of recombinant thyroid stimulating hormone in whole-body ${ }^{131}$ iodine clearance. World $\mathrm{J}$ Nucl Med. 2014;13:56-61.

14. Guo Y, Zhang Y, Chen Z, et al. Effects of recombinant human thyroid stimulating hormone on ${ }^{131} \mathrm{I}$ therapy for the treatment of differentiated thyroid cancer. Exp Ther Med. 2015;9:1847-1850.

15. Grenfell S, Roos D, Rijken J, et al. Comparison of effective I-131 half-life between thyroid hormone withdrawal and recombinant human thyroid-stimulating hormone for thyroid cancer: a retrospective study. $J$ Med Imaging Radiat Oncol. 2015;59:248-254.

16. Lassmann M, Hänscheid H, Chiesa C, et al. EANM Dosimetry Committee. EANM Dosimetry Committee series on standard operational procedures for pre-therapeutic dosimetry I: blood and bone marrow dosimetry in differentiated thyroid cancer therapy. Eur J Nucl Med Mol Imaging. 2008;35:1405-1412.

17. Inal BB, Oguz O, Emre T, et al. Evaluation of MDRD, Cockcroft-Gault, and CKD-EPI formulas in the estimated glomerular filtration rate. Clin Lab. 2014;60: 1685-1694.

18. Schlumberger M, Catargi B, Borget I, et al. Tumeurs de la thyroïde tefractaires network for the essai stimulation ablation equivalence trial. Strategies of radioiodine ablation in patients with low-risk thyroid cancer. N Engl J Med. 2012;366: 1663-1673.

19. Mallick U, Harmer C, Yap B, et al. Ablation with low-dose radioiodine and thyrotropin alfa in thyroid cancer. N Engl J Med. 2012;366:1674-1685.

20. Löffler M, Weckesser M, Franzius C, Kies P, Schober O. Iodine excretion during stimulation with rhTSH in differentiated thyroid carcinoma. Nuklearmedizin. 2003;42:240-243.

21. Coura-Filho GB, Willegaignon J, Buchpiguel CA, et al. Effects of thyroid hormone withdrawal and recombinant human thyrotropin on glomerular filtration rate during radioiodine therapy for well-differentiated thyroid cancer. Thyroid. 2015;25:1291-1296.

22. Villabona C, Sahun M, Roca M, et al. Blood volumes and renal function in overt and subclinical primary hypothyroidism. Am J Med Sci. 1999;318:277-280.

23. Karanikas G, Schutz M, Szabo M, et al. Isotopic renal function studies in severe hypothyroidism and after thyroid hormone replacement therapy. Am J Nephrol. 2004;24:41-45.

24. Ladenson PW, Braverman LE, Mazzaferri EL, et al. Comparison of administration of recombinant human thyrotropin with withdrawal of thyroid hormone for radioactive iodine scanning in patients with thyroid carcinoma. $N$ Engl J Med. 1997;337:888-896.

25. Haugen BR, Pacini F, Reiners C, et al. A comparison of recombinant human thyrotropin and thyroid hormone withdrawal for the detection of thyroid remnant or cancer. J Clin Endocrinol Metab. 1999;84:3877-3885.

26. Haugen BR, Cooper DS, Emerson $\mathrm{CH}$, et al. Expanding indications for recombinant human TSH in thyroid cancer. Thyroid. 2008;18:687-694.

27. Rosário PW, Borges MA, Purisch S. Preparation with recombinant human thyroid-stimulating hormone for thyroid remnant ablation with ${ }^{131} \mathrm{I}$ is associated with lowered radiotoxicity. J Nucl Med. 2008;49:1776-1782.

28. Hackshaw A, Kadalayil L, Mallick U. Well-being after radiation therapy in thyroid cancer. N Engl J Med. 2013;368:685-686.

29. Campennì A, Giovanella L, Pignata $\mathrm{SA}$, et al. Undetectable or low $(<1 \mathrm{ng} / \mathrm{ml})$ postsurgical thyroglobulin values do not rule out metastases in early stage differentiated thyroid cancer patients. Oncotarget. 2018;9:17491-17500.

30. Nascimento C, Borget I, Al Ghuzlan A, et al. Persistent disease and recurrence in differentiated thyroid cancer patients with undetectable postoperative stimulated thyroglobulin level. Endocr Relat Cancer. 2011;18:R29-R40.

31. Gonzalez Carvalho JM, Görlich D, Schober O, et al. Evaluation of ${ }^{131}$ I scintigraphy and stimulated thyroglobulin levels in the follow up of patients with DTC: a retrospective analysis of 1420 patients. Eur J Nucl Med Mol Imaging. 2017;44: 744-756.

32. Ravichandran R, Al Balushi N. Radioactive ${ }^{131}$ iodine body burden and blood dose estimates in treatment for differentiated thyroid cancer by external probe counting. World J Nucl Med. 2016;15:153-160. 